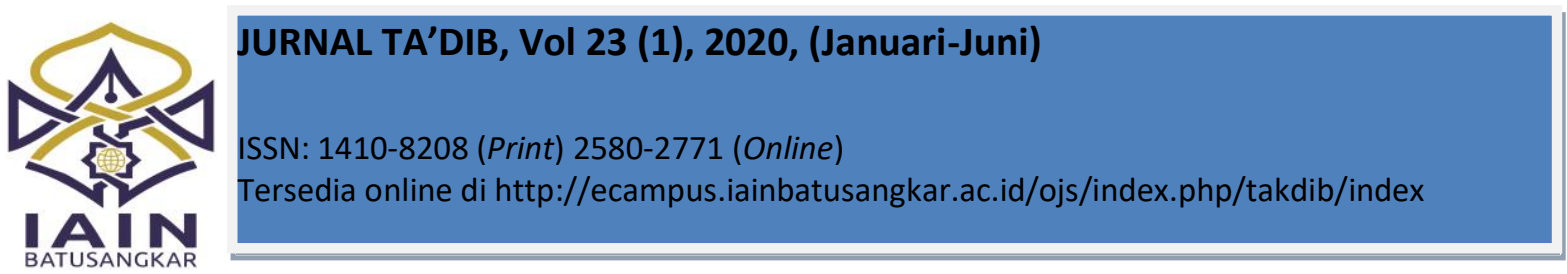

\title{
Analisis Tingkat Kepuasan Mahasiswa terhadap Layanan Administrasi Akademik Pegawai IAIN Kendari
}

\section{Sumianti \\ Universitas Ibnu Sina, \\ Batam, Indonesia \\ E-mail: sumiantiabang@yahoo.com}

\section{Syamsuddin*)}

Institut Agama Islam Negeri Kendari, Sulawesi Tenggara, Indonesia

E-mail: syamsuddinjufry@gmail.com

\section{Sitti Nurhalimah}

Institut Agama Islam Negeri Kendari, Sulawesi Tenggara, Indonesia

E-mail: imahnurhalimah12@gmail.com

\section{Hasbullah}

Institut Agama Islam Negeri Kendari,

Sulawesi Tenggara, Indonesia

E-mail: hasbullahiainkdi123@gmail.com
Abstract: Governance quality measurement of an educational institution is one of the main factors that can impact on the image of the college and the student loyalty. This article aims to describe and analyze the student satisfaction level of the academic administration services of IAIN Kendari staff. The research sample amounted to 88 students from 752 population numbers. The research instruments were structured using a service satisfaction indicator which refers to the tangible, reliability, responsiveness, assurance, and empathy aspects. The data were analyzed by using the Student Satisfaction Index analysis technique. The result of students' satisfaction of academic agency activities was in satisfactory category. Besides, an interesting empirical finding in this research was the level of students' satisfaction of the service positively correlates with the number of the employees. That is, the higher the number of employees, the higher the level of satisfaction of the service and vice versa. This indicates the need for the proportional distribution of academic administrative personnel in order to provide the more qualified academic service.

\section{Herlina}

Institut Agama Islam Negeri Kendari,

Sulawesi Tenggara, Indonesia

E-mail: herlinalin236@gmail.com

\section{Musjuliana}

Institut Agama Islam Negeri Kendari,

Sulawesi Tenggara, Indonesia

E-mail: musjuliana02@gmail.com

*) Corresponding Author

Keywords: College Student Satisfaction, Academic Administration Services

\section{PENDAHULUAN}

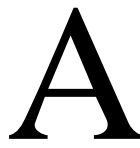
spek kualitas layanan adalah salah satu faktor utama yang dijadikan dasar pengukuran kualitas tata kelola suatu lembaga pendidikan. Setiap bentuk pelayanan yang diberikan oleh lembaga langsung dirasakan oleh konsumen, dalam hal ini mahasiswa selaku konsumen utama perguruan tinggi. Oleh karena itu, selaku penyedia jasa layanan pendidikan seharusnya perguruan tinggi berorientasi pada usaha peningkatan kepuasan mahasiswa, yakni dengan berusaha memenuhi kriteria pelayanan sesuai dengan harapan mahasiswa.

Pentingnya kepuasan yang dirasakan oleh stakeholder pada dasarnya telah dikaji oleh beberapa ahli manajemen pelayanan publik, khususnya yang terkait dengan upaya yang dilakukan untuk meningkatkan kepuasan stakeholder. Hasil kajian lapangan yang dilakukan oleh para ahli ditemukan beberapa hal yang terkait dengan kepuasan pada kualitas pelayanan. Misalnya, pengujian kualitas pelayanan yang 
mempengaruhi tingkat kepuasan pelanggan. Baik di bidang perusahaan berbasis profit seperti real estate (Dabholkar, P. A., 2005), industri supplier konsruksi bangunan (Kattiyapornpong, U. \& Limsiritong, K. 2010), bank (Mosahab, Mahamad and Ramayah, 2010) (Munusamy, Chelliah and Mun, 2010) (Kheng, Mahamad and Mosahab, 2010) maupun pada bidang pelayanan publik seperti lembaga kesehatan (Kui-Son, 2005), dan bahkan organisasi pendidikan termasuk perguruan tinggi (Alalak, Salih and Alnaser, 2012) (Tuan, 2012).

Dalam konteks layanan pendidikan pada perguruan tinggi, kepuasan stakeholder berorientasi pada persepsi kepuasan mahasiswa selaku konsumen utama jasa layanan pendidikan. Bahkan hasil penelitian menemukan bahwa perguruan tinggi kini sangat memperhatikan aspek pentingnya kepuasan karena keinginan mahasiswa untuk mendapatkan kualitas pelayanan pendidikan yang optimal dan sesuai dengan harapannya (Liana, 2016), serta berpengaruh terhadap loyalitas mahasiswa (Mulyawan, 2017) (Fikri, 2016) (Ali, F., 2016).

Berbagai perguruan tinggi kini menganggap bahwa tingkat kepuasan mahasiswa merupakan aspek yang tidak bisa diabaikan dalam mengukur kualitas layanan pendidikan. Hal tersebut dikarenakan perguruan tinggi telah menyadari bahwa aspek kepuasan mahasiswa merupakan hal yang kompetitif dan sebagai konsekuensi logis dari orientasi hukum ekonomi bahwa permintaan dan penawaran suatu lembaga berbasis profit sama halnya dengan perguruan tinggi yang berbasis nonprofit sehingga setiap perguruan tinggi harus menyiapkan strategi agar dapat menarik perhatian calon mahasiswa.

Lebih lanjut, Kitchroen menuturkan bahwa rendahnya kualitas pelayanan dapat mempengaruhi aspek keuangan dan eksistensi sebuah perguruan tinggi yang dapat dilihat pada menurunnya citra institusi dan menurunnya jumlah peminat calon mahasiswa baru (Kitchroen, K. (2004). Walaupun implikasi tersebut memang tidak langsung terjadi dan butuh jangka waktu yang lama namun paling tidak dampak negatif tersebut dipastikan akan terasa jika tidak diperhatikan oleh pimpinan institusi perguruan tinggi. Oleh karena itu, adanya kompetisi antar perguruan tinggi dalam suatu wilayah menjadi sangat penting untuk menilai tingkat kepuasan mahasiswa yang kemudian menjadi dasar bagi pimpinan perguruan tinggi untuk merumusan strategi dan program kebijakan untuk meningkatkan kepuasan mahasiswanya.

Institut Agama Islam Negeri (IAIN) Kendari juga memiliki tantangan yang sama meskipun memiliki keunggulan sebagai satusatunya Perguruan Tinggi Keagamaan Islam Negeri (PTKIN) di Provinsi Sulawesi Tenggara dan saat ini mendapatkan predikat Akreditasi B. Persaingan dengan perguruan tinggi lainnya di Kota Kendari dalam memperebutkan pangsa pasar calon mahasiswa seperti Universitas Haluoelo sebagai perguruan tinggi umum, Universitas Muhammadiyah Kendari (UMK), dan Universitas Nahdlatul Ulama Sulawesi Tenggara yang merupakan perguruan tinggi Islam swasta tentu saja harus menjadi perhatian serius pimpinan IAIN Kendari. Apalagi dilihat rasio jumlah pegawai administrasi yang hanya berjumlah 23 pegawai (termasuk dosen non PNS dan tenaga harian yang diperbantukan untuk memberikan layanan administrasi akademik) (Data Kepegawaian, 2010) yang melayani mahasiswa IAIN Kendari sebanyak 3.956 (mahasiswa aktif angkatan 2014-2018) yang tersebar di semua fakultas, yakni Fakultas Tarbiyah dan Ilmu Keguruan (FTIK), Fakultas Syariah (Faksyar), Fakultas Ushuluddin dan Dakwah (FUAD), serta Fakultas Ekonomi dan Bisnis Islam (FEBI). Hal tersebut berarti rasio pegawai administrasi akademik dengan mahasiswa sebesar 1:172 (Data Kemahasiswaan, 2010).

Selain itu, meskipun pada dasarnya pimpinan telah menerapkan berbagai strategi dalam rangka peningkatan kualitas pelayanan administrasi akademik yang tentu saja berorientasi pada peningkatan kepuasan mahasiswa. Misalnya, memberdayakan dosen tetap non PNS sebagai petugas 
administrasi, dan administrasi akademik berbasis media daring (online) melalui alamat website www.iainkendari.ac.id dimana mahasiswa memiliki akun masingmasing untuk mengakses KRS (Kartu Rencana Studi) dalam hal ini untuk melakukan penawaran mata kuliah, penegecekan nilai berupa KHS (Kartu Hasil Studi), serta untuk mengetahui dan mencetak trankrip nilai. Namun hal tersebut belum menjadi jaminan terhadap tingkat kepuasan mahasiswa. Hal tersebut dikarenakan tidak semua kebutuhan administrasi akademik dapat dilakukan secara daring. Misalnya, surat pengantar penelitian, dan surat keterangan aktif kuliah.

Bahkan jika merujuk pada konsep dimensi kualitas pelayanan yang diuraikan oleh pakar manajemen maka dapat dengan jelas diketahui bahwa aspek pelayananan bukan hanya tersedianya layanan administrasi tetapi lebih komprehensif dari itu adalah perlunya mewujudkan 5 (lima) dimensi atau aspek kualitas layanan. Dimensi kualitas layanan yang dimaksud adalah 1) tangible, yaitu tersedianya wujud dari ketersediaan sarana fisik, perangkat, pegawai, dan perangkat komunikasi, 2) reliability, yaitu akurasi dalam pelayanan, 3) responsiveness, yaitu kemauan untuk membantu melayani sesegera mungkin, 4) assurance, yaitu tingkat keramahan pegawai dan adanya kepastian penyelesaian layanan yang dibutuhkan, 5) empathy, rasa peduli dan perhatian kepada konsumen (Athanassopoulos, Gounaris and Stathakopoulos, 2001).

Berdasarkan berbagai hal di atas maka peneliti merasa suatu hal yang penting dan menarik untuk menganalisis tingkat kepuasan mahasiswa terhadap kualitas pelayanan administrasi akademik pegawai IAIN Kendari.

\section{METODE PENELITIAN}

Penelitian kuantitatif deskriptif ini menggunakan metode survei. Populasi yang berjumlah 752 merupakan mahasiswa angkatan 2015 bagi strata S1 dan angkatan 2017 bagi strata S2 IAIN Kendari. Populasi tersebut dipilih karena mahasiswa pada angkatan tersebut diasumsikan telah mendapatkan semua jenis layanan administrasi akademik. Selanjutnya, sampel ditentukan dengan menggunakan rumus Slovin dengan presisi (derajat kesalahan) sebesar $10 \%$, yakni sebanyak 88 mahasiswa yang secara proporsional terbagi di semua fakultas dan pascasarjana yang ada di IAIN Kendari. Pengumpulan data melalui angket. Angket disusun menggunakan indikator kepuasan pelayanan yang mengacu pada teori Gaspersz, yakni aspek tangible, reliability, responsiveness, assurance, dan empaty (Gaspersz, V. (1997). Instrumen berupa angket ini telah melalui uji validitas dan relibilitas kepada 20 orang mahasiswa di luar sampel penelitian sebelum disebarkan ke seluruh responden. Adapun teknik untuk menganalisis data yang digunakan adalah teknik analisis Indeks Kepuasan Mahasiswa (IKM) yang merupakan teknik analisis kuantitatif deskriptif yang menampilkan persentase kepuasan mahasiswa selaku pengguna layanan administrasi perguruan tinggi melalui penggunaan rumus CSI yang diadaptasi dari Bhote.

\section{HASIL DAN PEMBAHASAN}

Hasil perhitungan tingkat kepuasan mahasiswa melalui penggunaan rumus Indeks Kepuasan Mahasiswa (IKM) berdasarkan lima indikator kepuasan pelayanan (tangible, reliability, responsiveness, assurance, dan empaty) diperoleh persentase sebagaimana tabel dan diagram berikut ini:

Tabel 1. Tingkat Kepuasan Mahasiswa Setiap Fakutas dan Pascasarjana IAIN Kendari

\begin{tabular}{|c|c|c|}
\hline No. & Indikator Kepuasan & $\begin{array}{r}\text { IKM } \\
\text { S/(5xI) }\end{array}$ \\
\hline 1 & Fak. Tarbiyah dan Ilmu Keguruan (FTIK) & 0.81 \\
\hline 2 & Fak. Ekonomi dan Bisnis Islam (FEBI) & 0.84 \\
\hline 3 & Fak. Ushuluddin Adab dan Dakwah (FUAD) & 0.83 \\
\hline 4 & Fak. Syariah (Faksyar) & 0.86 \\
\hline 5 & Pascasarjana & 0.88 \\
\hline \multirow{2}{*}{\multicolumn{2}{|c|}{ Total }} & 0.810 \\
\hline & & $81 \%$ \\
\hline
\end{tabular}




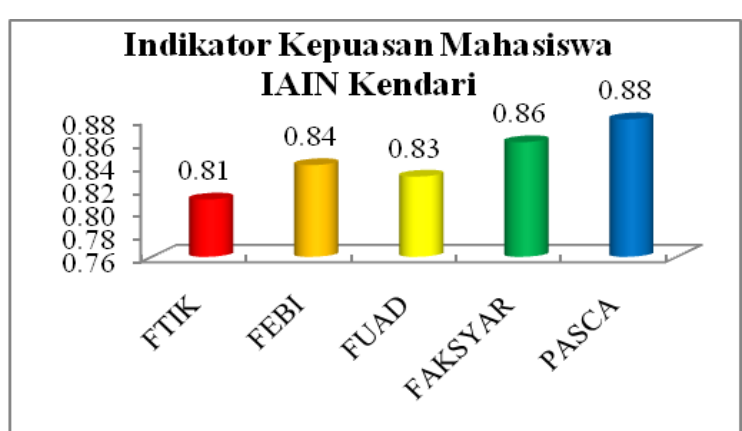

Gambar. 1 Diagram Kepuasan Mahasiswa IAIN Kendari

Berdasarkan tabel dan gambar di atas dapat diketahui dengan jelas bahwa pascasarjana memiliki tingkat kepuasan layanan mahasiswa paling tinggi, yakni sebesar $88 \%$ dan yang terendah adalah Fakultas Tarbiyah dan Ilmu Keguruan (FTIK) IAIN Kendari.

Adapun tingkat kepuasan berdasarkan kriteria atau indikator kepuasan layanan (tangible, reliability, responsiveness, assurance, dan empaty) pada setiap fakultas dan pascasarjana sebagai berikut:

1. Tingkat kepuasan mahasiswa terhadap kualitas pelayanan akademik pegawai tata usaha Fakultas Tarbiyah dan Ilmu Keguruan (FTIK) IAIN Kendari

Hasil perhitungan tingkat kepuasan mahasiswa terhadap pelayanan pegawai tata usaha FTIK dapat dilihat pada tabel berikut ini:

Tabel 2. Tingkat Kepuasan Mahasiswa FTIK

\begin{tabular}{||l|l|c||}
\hline \hline No. & Indikator Kepuasan & $\begin{array}{c}\text { IKM } \\
\text { S/(5xI) }\end{array}$ \\
\hline 1 & Reliability & 0.811 \\
\hline 2 & Responsiveness & 0.812 \\
\hline 3 & Assurance & 0.806 \\
\hline 4 & Empaty & 0.807 \\
\hline 5 & Tangibles & 0.816 \\
\hline \hline \multicolumn{2}{|c|}{ Total } & $\mathbf{0 . 8 1 0}$ \\
\hline & & $\mathbf{8 1 \%}$ \\
\hline
\end{tabular}

Tabel di atas memberikan deskripsi bahwa nilai total IKM mahasiswa terhadap layanan administrasi akademik pegawai TU FTIK adalah sebesar $81 \%$ yang berarti bahwa mahasiswa merasa sangat puas terhadap kualitas layanan yang diberikan oleh pegawai. Hal ini memberikan indikasi yang jelas bahwa kualitas layanan TU FTIK berdasarkan seluruh kriteria atau indikator (reliability, responsiveness, assurance, empaty, dan tangibles) telah dianggap sangat baik oleh mahasiswa.

Selain itu, berdasarkan peringkat pada setiap indikator kepuasan layanan tersebut maka dapat diketahui bahwa dimensi tangibles yang dianggap paling memuaskan dengan nilai IKM sebesar 81,6\%. Indikator ini merupakan kepuasan mahasiswa terhadap tersedianya wujud fasilitas, perangkat, staf, dan media komunikasi. Adapun indikator yang mendapatkan persentase paling rendah adalah assurance yang merupakan aspek kemampuan, kesopanan dan sikap dapat dipercaya yang dimiliki para pegawai, serta bebas dari bahaya, resiko ataupun keraguraguan.

2. Tingkat Kepuasan Mahasiswa Fakultas Ekonomi dan Bisnis Islam (FEBI) IAIN Kendari

Hasil perhitungan tingkat kepuasan mahasiswa terhadap pelayanan pegawai tata usaha FEBI disajikan pada tabel berikut ini:

Tabel 3. Tingkat Kepuasan Mahasiswa FEBI

\begin{tabular}{||l|l|c||}
\hline No. & Indikator Kepuasan & $\begin{array}{c}\text { IKM } \\
\mathbf{S} /(\mathbf{5 x I})\end{array}$ \\
\hline 1 & Reliability & 0.84 \\
\hline 2 & Responsiveness & 0.85 \\
\hline 3 & Assurance & 0.83 \\
\hline 4 & Empaty & 0.83 \\
\hline 5 & Tangibles & 0.84 \\
\hline \hline \multicolumn{2}{|c|}{ Total } & $\mathbf{0 . 8 4}$ \\
\hline \multicolumn{2}{|c|}{} & $\mathbf{8 4 \%}$ \\
\hline
\end{tabular}

Tabel di atas memberikan deskripsi bahwa nilai total IKM mahasiswa terhadap layanan administrasi akademik pegawai TU FEBI adalah sebesar 0,84 atau $84 \%$ yang menggambarkan bahwa pada umumnya mahasiswa sangat puas terhadap layanan yang diberikan oleh pegawai. Hal tersebut mengindikasikan secara jelas bahwa kualitas layanan TU FEBI berdasarkan seluruh kriteria atau indikator (reliability, responsiveness, assurance, empaty, dan tangibles) telah dirasakan sangat baik oleh mahasiswa.

Berdasarkan urutan perolehan skor setiap indikator kepuasan layanan di atas dapat diketahui dengan jelas bahwa aspek responsiveness adalah indikator yang dianggap paling memuaskan dengan nilai IKM sebesar 0.85 atau $85 \%$ yang merupakan 
kepuasan mahasiswa terhadap kemauan pegawai membantu dan memberikan layanan secara tepat dan cepat. Adapun indikator yang mendapatkan persentase paling rendah adalah assurance dan empathy. Indikator assurance merupakan aspek kemampuan, sopan santun dan sikap dapat dipercaya yang dimiliki pegawai, serta bebas dari kekhawatiran, resiko ataupun keragu-raguan. Empathy adalah aspek kemudahan, komunikasi yang baik, dan perhatian yang dianggap tulus terhadap kebutuhan pelanggan

3. Analisis Tingkat Kepuasan Mahasiswa

Fakultas Syariah (Faksyar) IAIN Kendari

Hasil perhitungan tingkat kepuasan mahasiswa terhadap pelayanan pegawai tata usaha fakultas syariah dapat dilihat pada tabel berikut ini:

Tabel 4. Tingkat Kepuasan Mahasiswa Faksyar

\begin{tabular}{||l|l|c||}
\hline \multirow{2}{*}{ No. } & Indikator Kepuasan & $\begin{array}{c}\text { IKM } \\
\text { S/(5xI) }\end{array}$ \\
& & 0.84 \\
\hline 1 & Reliability & 0.90 \\
\hline 2 & Responsiveness & 0.87 \\
\hline 3 & Assurance & 0.90 \\
\hline 4 & Empaty & 0.81 \\
\hline 5 & Tangibles & $\mathbf{0 . 8 6}$ \\
\hline \hline \multicolumn{2}{|c|}{ Total } & $\mathbf{8 6 \%}$ \\
\cline { 2 - 3 } & &
\end{tabular}

Tabel di atas menyajikan deskripsi bahwa nilai total IKM mahasiswa terhadap layanan administrasi akademik pegawai TU Faksyar adalah sebesar 0,84 atau $84 \%$ yang berarti bahwa mahasiswa merasa sangat puas terhadap layanan pegawai. Hal ini menunjukkan bahwa kualitas layanan TU Faksyar berdasarkan seluruh kriteria atau indikator (reliability, responsiveness, assurance, empathy, dan tangibles) telah dirasakan sangat baik oleh mahasiswa.

Berdasarkan peringkat pada setiap indikator kepuasan layanan pada tabel di atas diketahui dengan jelas bahwa indikator atau dimensi empathy dan responsiveness yang dianggap paling memuaskan dengan nilai IKM sebesar 0.90 atau $90 \%$ yang merupakan kepuasan mahasiswa terhadap kepedulian dan perhatian pegawai terhadap mahasiswa saat membutuhkan layanan administrasi akademik dan kemampuan pegawai dalam membantu serta memberikan layanan administrasi akademik dengan cepat dan tepat. Adapun indikator yang mendapatkan persentase paling rendah adalah tangibles yang merupakan aspek ketersediaan fasilitas fisik, perlengkapan, dan sarana komunikasi yang memadai.

4. Analisis Tingkat Kepuasan Mahasiswa Fakultas Ushuluddin, Adab, dan Dakwah (FUAD) IAIN Kendari

Hasil perhitungan tingkat kepuasan mahasiswa terhadap pelayanan pegawai tata usaha FUAD ditampilkan pada tabel berikut ini:

Tabel 5. Tingkat Kepuasan Mahasiswa FUAD

\begin{tabular}{|c|c|c|}
\hline No. & Indikator Kepuasan & $\begin{array}{c}\text { IKM } \\
\text { S/(5xI) }\end{array}$ \\
\hline 1 & Reliability & 0.76 \\
\hline 2 & Responsiveness & 0.83 \\
\hline 3 & Assurance & 0.82 \\
\hline 4 & Empaty & 0.87 \\
\hline 5 & Tangibles & 0.86 \\
\hline \multicolumn{2}{|r|}{ Total } & $\mathbf{0 . 8 3}$ \\
\hline
\end{tabular}

Tabel diagram di atas menunjukkan bahwa nilai total IKM mahasiswa terhadap layanan administrasi akademik pegawai TU FUAD adalah sebesar 0,83 atau $83 \%$ yang berarti bahwa mahasiswa merasa sangat puas terhadap layanan pegawai. Hal ini menunjukkan bahwa kualitas layanan TU FUAD berdasarkan seluruh kriteria atau indikator (reliability, responsiveness, assurance, empaty, dan tangibles) telah dipersepsikan sangat baik oleh mahasiswa.

Berdasarkan peringkat pada setiap indikator atau dimensi kepuasan layanan di atas maka dapat diketahui bahwa indikator atau dimensi empathy yang dianggap paling memuaskan dengan nilai IKM sebesar 0.87 atau $87 \%$ yang merupakan kepuasan mahasiswa terhadap adanya kepedulian dan perhatian pegawai terhadap mahasiswa saat membutuhkan layanan administrasi akademik. Adapun indikator yang mendapatkan persentase paling rendah adalah reliability yang merupakan aspek kemampuan pegawai melayani secara cepat dan tepat serta sesuai dengan yang telah dijanjikan.

5. Analisis Tingkat Kepuasan Mahasiswa Pascasarjana IAIN Kendari 
Hasil perhitungan tingkat kepuasan mahasiswa terhadap pelayanan pegawai tata usaha Pascasarjana dapat dilihat pada tabel berikut ini:

Tabel 6. Tingkat Kepuasan

Mahasiswa Pascasarjana

\begin{tabular}{||c|l|c||}
\hline \multirow{2}{*}{ No. } & \multicolumn{1}{|l|}{ Indikator Kepuasan } & $\begin{array}{c}\text { IKM } \\
\mathbf{S} /(\mathbf{5 x I})\end{array}$ \\
\hline 1 & Reliability & 0.89 \\
\hline 2 & Responsiveness & 0.85 \\
\hline 3 & Assurance & 0.87 \\
\hline 4 & Empaty & 0.88 \\
\hline 5 & Tangibles & 0.89 \\
\hline \hline \multicolumn{2}{|c|}{ Total } & $\mathbf{0 . 8 8}$ \\
\hline \multicolumn{2}{|c|}{} & $\mathbf{8 8 \%}$ \\
\hline
\end{tabular}

Dari tabel di atas dapat dikethaui deskripsi yang jelas bahwa nilai total IKM mahasiswa terhadap layanan administrasi akademik pegawai TU Pascasarjana adalah sebesar 0,88 atau $88 \%$ yang berarti bahwa mahasiswa merasa sangat puas terhadap layanan pegawai. Hal ini menunjukkan bahwa kualitas layanan TU Pascasarjana berdasarkan seluruh kriteria atau indikator (reliability, responsiveness, assurance, empaty, dan tangibles) telah dianggap sangat baik oleh mahasiswa.

Berdasarkan peringkat pada setiap indikator atau dimensi kepuasan layanan di atas maka dapat diketahui bahwa indikator atau dimensi reliability dan tangibles yang dianggap paling memuaskan dengan nilai IKM sebesar 0.89 atau $89 \%$ yang merupakan kepuasan mahasiswa terhadap kemampuan pegawai dalam memberikan pelayanan yang akurat dan terpercaya, serta adanya wujud dari fasilitas yang disediakan, perangkat, staf, dan media komunikasi yang disediakan. Adapun indikator yang mendapatkan persentase paling rendah adalah responsiveness yang merupakan aspek keinginan para pegawai untuk membantu menangani layanan administrasi akademik mahasiswa dengan tanggap.

Berdasarkan berbagai pemaparan data hasil temuan di atas maka dapat disimpulkan bahwa pascasarjana memiliki tingkat kepuasan layanan mahasiswa paling tinggi, yakni sebesar $88 \%$ dan terendah adalah Fakultas Tarbiyah dan Ilmu Keguruan (FTIK) IAIN Kendari. Hasil ini tentu bukan untuk sekedar mengetahui unit kerja yang memperolah skor tertinggi dan terendah karena penelitian ini sejatinya untuk menelaah secara mendalam berbagai hal yang dapat dilakukan untuk meningkatkan mutu pelayanan administrasi akademik bagi mahasiswa. Selain itu, rasio jumlah pegawai dengan mahasiswa (S1 angkatan 2015, dan S2 angkatan 2017) di setiap unit kerja yang jauh berbeda. Misalnya, rasio di FTIK sebesar 12:449 atau 1:37, FEBI sebesar 5:141 atau 1:28, FUAD sebesar 5:51 atau 1:10, Syariah 7:58 atau 1:8, dan Pascasarjana 7:53 atau 1:7. Begitupula dilihat hasil penelitian salah seorang mahasiswa yang dilakukan di FTIK yang mengambil sampel mahasiswa angkatan 2014 menunjukkan hasil sebesar 67,74\% (Hasbullah, 2018). Hal tersebut berarti bahwa tingkat kepuasan mahasiswa usaha mengalami peningkatan sebesar 32,26\%.

Rasio tersebut menunjukkan bahwa semakin tinggi rasio jumlah pegawai dengan mahasiswa maka tingkat kepuasan layanan akan semakin tinggi, dan begitu juga sebaliknya. Hal ini mengindikasikan perlunya distribusi tenaga administrasi akademik yang lebih proporsional dengan jumlah mahasiswa yang harus dilayani agar kualitas layanan yang diberikan kepada mahasiswa dapat lebih baik.

Pengukuran persepsi kepuasan mahasiswa terhadap layanan yang disediakan oleh suatu perguruan tinggi, termasuk dalam penyediaan layanan administrasi pendidikan adalah aspek yang sangat penting untuk diperhatikan setiap tahun. Hal tersebut dikarenakan dalam konteks layanan pendidikan pada perguruan tinggi, kepuasan stakeholder berorientasi pada kepuasan mahasiswa selaku konsumen utama jasa layanan pendidikan. Bahkan berbagai referensi memaparkan bahwa perguruan tinggi kini lebih memperhatikan aspek pentingnya kepuasan mahasiswa. Berbagai perguruan tinggi kini menganggap bahwa tingkat kepuasan mahasiswa merupakan bagian yang sangat penting dalam menakar kualitas layanan pendidikan. Hal tersebut dikarenakan perguruan tinggi telah menyadari bahwa aspek kepuasan 
mahasiswa merupakan hal yang kompetitif dan sebagai konsekuensi logis dari orientasi hukum ekonomi bahwa permintaan dan penawaran layaknya pada perguruan tinggi sebagai organisasi layaknya sebuah perusahaan berbasis profit sehingga setiap perguruan tinggi harus menyiapkan strategi agar dapat menarik perhatian calon mahasiswa.

Di sisi lain, tingkat kepuasan mahasiswa terhadap pelayanan akan memiliki manfaat terhadap sebuah lembaga atau perguruan tinggi. Kepuasan pelayanan oleh penerima jasa dapat dicapai jika penerima jasa pelayanan merasa sudah sesuai dengan ekpektasi dan kebutuhannya. Selain itu, implikasi positif yang akan diterima oleh lembaga atau perguruan tinggi terhadap pelayanan yang baik yang diberikan kepada mahasiswa adalah akan memberikan manfaat berupa peningkatan jumlah mahasiswa ke lembaga atau institusi kita, karena mahasiswa akan bersedia memasarkan dan menceritakan institusi atau lembaga kita kepada calon mahasiswa terkait pelayanan baik yang telah diberikan kepada mereka. Oleh karena itu, selayaknya penyelenggara pendidikan saat ini berupaya meningkatkan kualitas pelayanan yang disediakan kepada mahasiswa melihat dewasa ini persaingan antar perguruan tinggi semakin meningkat.

Selain itu, mahasiswa memang memiliki hak untuk memperoleh pelayanan yang terbaik, dan berhak mendapatkan fasilitas yang dimiliki perguruan tinggi. Hal ini didasarkan pada konsep pelayanan persepsi satakeholder dimana berbagai layanan yang disediakan akan menimbulkan persepsi kepuasan dari mahasiswa jika ekspektasi mahasiswa terhadap layanan terpenuhi sesuai kenyataan yang dialami.

Kualitas pelayanan juga dianggap dapat mempengaruhi berbagai keputusan sekaligus menjadi connector terakhir pada rantai aktivitas penerapan total quality management perguruan tinggi (Mubasit, M., 2015). Philip Kotler menguraikan 5 (lima) aspek yang mempengaruhi suatu kualitas layanan (Supranto, J., 2006), yaitu:
1. Reliability (kehandalan), yaitu kemampuan pegawai menyelenggarakan pelayanan yang telah disepakati secara akurat dan terpercaya.

2. Responsiveness (daya tanggap), yaitu kemampuan pegawai untuk memberikan bantuan jasa secara cepat.

3. Assurance (keyakinan), yaitu kemampuan, pengetahuan, dan sikap pegawai dalam yang menumbuhkan kepercayaan.

4. Empathy (empati), yaitu kepedulian dan perhatian pegawai.

5. Tangibles (berwujud), yaitu adanya wujud fisik dari fasilitas yang disediakan, peralatan, personel dan media komunikasi yang disediakan.

Selain itu, keberhasilan pelayanan ditentukan berdasarkan tingkat kepuasan penerima pelayanan yang dapat dicapai apabila penerima pelayanan memperoleh pelayanan sesuai dengan kebutuhan dan harapan. Oleh karena itu, Menteri Aparatur Negara dan Reformasi Birokrasi melalui keputusan Menpan No. 63 Tahun 2004 mengamanatkan agar setiap penyelenggara pelayanan secara berkala melakukan survei indeks kepuasan masyarakat (Ratminto, A. S. W. (2005).

Di sisi lain, hasil peneltian juga menunjukkan bahwa belum ada dimensi atau aspek yang memiliki skor $100 \%$. Hal ini tentu saja perlu ditindaklanjuti secara strategis oleh pimpinan IAIN Kendari, khususnya oleh pimpinan fakultas dan pascasarjana. Adapun langkah strategis yang dapat dilakukan oleh pimpinan IAIN Kendari dapat merujuk pada pendapat yang dikemukakan oleh Fandi Tjiptono (Fandy, T., 1997), diantaranya adalah:

1. Strategi superior customer service, yaitu pemberian pelayanan yang lebih unggul dari pesaing. Dalam hal ini perguruan tinggi bisa menawarkan beberapa keunggulan yang tidak dimiliki tempat lain. Misalnya, optimalisasi semua pelayanan administrasi akademik berbasis online (media daring). Apalagi setiap tahun langkah ini memang telah 
mengalami pembenahan secara bertahap oleh pimpinan IAIN Kendari.

2. Strategi conditional guarantees atau extraordinary guarantees, yaitu strategi yang berintikan untuk memberikan kepuasan kepada pelanggan yang akhirnya akan menjadi sumber penyempurnaan mutu produk atau jasa dan kinerja lembaga. Strategi ini dapat digunakan oleh pimpinan IAIN Kendari dengan menyediakan standar operasional prosedur (SOP) yang jelas pada setiap item layanan administrasi akademik dalam memberikan layanan kepada stakeholdernya. Melalui standar tersebut, IAIN Kendari dapat memberikan jaminan berupa pelayanan yang prima. Selain itu, strategi akan meningkatkan motivasi para pegawai untuk mencapai tingkat kinerja yang lebih baik dari pada sebelumnya. Garansi atau jaminan mutlak dirancang untuk meringankan risiko/kerugian pelanggan. Garansi tersebut menjanjikan kualitas prima dan kepuasan pelanggan, sehingga memaksa lembaga untuk memberikan yang terbaik dan meraih loyalitas pelanggan. Fungsi utamanya adalah untuk meminimalisir kekecewaan pelanggan terhadap layanan oleh lembaga yang bersangkutan. Suatu garansi harus memenuhi beberapa kriteria agar dapat dikatakan baik, diantaranya adalah realistis, sederhana, komunikatif, mudah dipahami, tidak membebani pelanggan, fokus pada kebutuhan pelanggan, dan adanya standar kinerja yang jelas.

3. Strategi penanganan keluhan, yaitu setrategi yang mampu mengubah seorang pelanggan yang tidak puas menjadi puas, (Sarjono, 2007) manfaat lainnya antara lain:
a. Memiliki kesempatan untuk memperbaiki persepsi pelanggan yang merasa kecewa;
b. Terhindar dari citra negatif;
c. Aspek yang perlu segera dibenahi dapat dideteksi;
d. Sumber masalah operasional dapat diketahui;

e. Tertantang untuk menyediakan layanan yang lebih berkualitas.

Sementara itu, Terdapat empat hal yang penting dalam menangani keluhan (Gaspers, V. 2008), yaitu sebagai berikut:

a. Empati pada pelanggan, khususnya yang marah;

b. Tingkat kecepatan penanganan keluhan;

c. Berlaku adil dalam menangani setiap keluhan;

d. Kemudahan komunikasi (Nasution, 2016).

Jika aspek penting tersebut di atas dilaksanakan secara baik maka kekecewaan mahasiswa IAIN Kendari selaku pelanggan dapat diminimalisir.

4. Strategi peningkatan kinerja lembaga, yaitu berbagai upaya strategis memasukkan unsur kemampuan memberikan layanan yang memuaskan kepada pelanggan ke dalam sistem penilaian prestasi karyawan. Hal ini juga bisa membuat pegawai lebih displin berada di tempat kerja. Begitupula, pegawai akan dapat lebih terbuka untuk berkomunikasi melalui telepon dan media sosial dengan mahasiswa terkait dengan pemberian layanan administrasi akademik.

5. Menerapkan Quality Function Depliyment (QFD), yaitu menyusun rancangan proses sebagai tindaklanjut kebutuhan pelanggan. Strategi ini perlu dilakukan secara terstruktur untuk menentukan kebutuhan pelanggan dan menginterpretasikannya ke dalam kebutuhan teknis yang relevan dan memastikan semua elemen unit kerja memahami dan melaksanakannya.

Implikasi positif yang dapat diperoleh dari penerapan strategi ini adalah dapat memberikan berbagai hasil sebagai berikut:

a. Efektivitas komunikasi antar unit kerja yang semakin baik;

b. Espektasi pelanggan dapat diproses langsung ke unit kerja yang bertugas secara teknis; 
c. Terhindar dari perubahan sistem secara luas;

d. Meningkatkan kualitas sistem;

e. Efisiensi biaya dan waktu;

f. Mampu mengidentifikasi menyelesaikan kebutuhan yang dikeluhkan oleh pelanggan.

Pekerjaan dari tim $Q F D$ ini adalah mengakomodir berbagai informasi atau isu dari pelanggan. Berbagai isu tersebut biasanya berupa:

1) Kebutuhan dan keinginan pelanggan;

2) Rancangan produk dan proses operasionalnya;

3) Pengendalian proses;

4) Pemantauan secara berkala;

5) Pengukuran secara kritis. (Peter, J. P., \& Olson, J. C., 2000).

Adapun salah satu langkah konkrit yang bisa dilakukan oleh pimpinan IAIN Kendari melalui strategi ini adalah dengan mengintruksikan kepada pegawai yang akan atau sedang mengikuti Pendidikan dan Latihan Kepemimpinan (Diklatpim) untuk menyusun proyek perubahan berbasis peningkatan kualitas layanan administrasi akademik. Proyek perubahan tersebut hendaknya melibatkan mahasiswa agar lebih efektif dan mampu mengatasi berbagai keluhan mahasiswa terkait layanan yang diberikan oleh pegawai.

\section{KESIMPULAN DAN REKOMENDASI}

Penelitian ini menegaskan bahwa mahasiswa merasa puas terhadap layanan administrasi akademik pegawai tata usaha IAIN Kendari di setiap fakultas dan pascasarjana. Hal ini menunjukkan pelayanan pegawai tata usaha IAIN Kendari dapat dikategorikan baik. Selain itu, temuan empirik yrang menarik dalam penelitian ini adalah tingkat kepuasan terhadap layanan berbanding lurus dengan rasio pegawai dengan mahasiswa. Artinya, semakin tinggi rasio jumlah pegawai dengan mahasiswa maka semakin tinggi pula tingkat kepuasan layanan dan begitupula sebaliknya. Hal ini mengindikasikan perlunya distribusi tenaga administrasi akademik yang lebih proporsional dengan jumlah mahasiswa yang harus dilayani agar kualitas layanan yang diberikan kepada mahasiswa dapat lebih baik. Adapun hal lain yang dapat dilakukan untuk meningkatkan kepuasan layanan adalah melalui penerapan berbagai strategi yang dapat dijadikan alternatif pilihan baik bagi pimpinan IAIN Kendari maupun perguruan tinggi lain yang ingin meningkatkan kualitas layanan terhadap mahasiswa, yaitu strategi superior customer service, strategi conditional guarantees, strategi penanganan keluhan, dan strategi peningkatan kinerja lembaga, dan menerapkan quality function depliyment $(Q F D)$. Namun perlu penelitian lanjutan, misalnya penelitian strategi yang paling efektif dalam meningkatkan kualitas pelayanan adminsitrasi akademik pada lembaga pendidikan.

\section{REFERENSI}

Ali, F., Zhou, Y., Hussain, K., Nair, P. K., \& Ragavan, N. A. (2016). Does higher education service quality effect student satisfaction, image and loyalty? Quality Assurance in Education, 24 No. 1, pp. 70-94. https://doi.org/10.1108/QAE-022014-0008

Athanassopoulos, A., Gounaris, S. and Stathakopoulos, V. (2001) 'Behavioural responses to customer satisfaction: an empirical study', European Journal of Marketing, 35(5/6), pp. 687-707.

Al-alak, B. A., Salih, A. and Alnaser, M. (2012) 'Assessing the Relationship Between Higher Education Service Quality Dimensions and Student Satisfaction Professor of marketing College Of Business Management and Accounting Department', Australian Journal of Basic and Applied Sciences, 6(1), pp. 156-164.

Dabholkar, P. A., \& Overby, J. W. (2005) 'Linking process and outcome to service quality and customer satisfaction evaluations: An investigation of real estate agent service', International Journal of Service Industry Management. Edited by O. J. W. Emerald Group Publishing Limited, 16(1), pp. 10-27. 
Fandy, T. (1997). Prinsip-Prinsip Total Quality Service. Yogyakarta: Andi.

Fikri, S., Wiyani, W., \& Suwandaru, A. (2016). Pengaruh Kualitas Pelayanan Terhadap Kepuasan Dan Loyalitas Mahasiswa (Studi pada Mahasiswa Strata I Fakultas Ilmu Sosial dan Ilmu PolitikUniversitas Malang). Jurnal Bisnis dan Manajemen, 3(1).

Gaspersz, V. (2007). Manajemen Kualitas Dalam Industri Jasa: Strategi untuk Memenangkan Persaingan Global. Jakarta: PT. Gramedia Pustaka Utama.

Gaspersz Vincent. (2008). The Executive Guide to Implementing Lean Six Sigma. Jakarta: PT. Gramedia Pustaka Utama.

Hasbullah, (2018). Analisis Tingkat Kepuasan Mahasiswa Terhadap Pelayanan Administrasi Tata Usaha (TU) Fakultas Tarbiyah Dan Ilmu Keguruan (FATIK) Institut Agama Islam Negeri (IAIN) Kendari, (Bachelor) IAIN Kendari. Retrieved from http://digilib.iainkendari.ac.id/1399/

Kattiyapornpong, U. \& Limsiritong, K. (2010). Assessing service quality dimensions: a study of the construction supplier industry in Thailand. TMC Academic Journal, 5 (1), 23-34.

Kheng, L. L., Mahamad, O. and Mosahab, R. (2010) 'The Impact of Service Quality on Customer Loyalty: A Study of Banks in Penang, Malaysia', International Journal of Marketing Studies, 2(2), pp. 57-66.

Kitchroen, K. (2004). Literature review: Service quality in educational institutions. ABAC journal, 24(2).

Kui-Son, C. (2005) 'The service quality dimensions and patient satisfaction relationships in South Korea: comparisons across gender, age and types of service', Journal of Services Marketing. Edited by L. Hanjoon and M. Laroche. Emerald Group Publishing Limited, 19(3), pp. 140-149.

Liana, N. A., Benty, D. D. N., \& Supriyanto, A. (2016). Analisis Faktor Yang mempengaruhi kepuasan orang tua peserta didik terhadap layanan pendidikan. Jurnal Manajemen Pendidikan, 25.

Mosahab, R., Mahamad, O. and Ramayah, T. (2010) 'Service Quality, Customer Satisfaction and Loyalty: a Test of Mediation', International Business Research, 3(4), pp. 72-80.

Mubasit, M. (2015). Menuju Kepuasan Layanan Akademik Perguruan Tinggi. Bina'al-Ummah, 10(1).

Mulyawan, A., \& Rinawati, R. (2017). Pengaruh Kualitas Layanan Akademik Terhadap Kepuasan Mahasiswa Serta Implikasinya Pada Loyalitas Mahasiswa (Studi Pada Sekolah Tinggi Manajemen Informatika Dan Komputer Di Kota Bandung). Jurnal Ekonomi, Bisnis \& Entrepreneurship, 10(2), 119-131.

Munusamy, J., Chelliah, S. and Mun, H. (2010) 'Service quality delivery and its impact on customer satisfaction in the banking sector in Malaysia', International Journal of Innovation, ..., 1(4), pp. 398-404.

Nasution, M. N. (2016). A Deming Cycle as a Tool of Improving A Continuous Service Quality. Indonesian Management and Accounting Research (IMAR), 5(1), 53-78.

Peter, J. P., \& Olson, J. C. (2000). Consumer Behavior: Perilaku Konsumen Dan Strategi Pemasaran. Jakarta: Erlangga.

Ratminto, A. S. W. (2005). Manajemen Pelayanan. Yogyakarta: Pustaka Pelajar.

Sarjono, Y. (2007). Faktor-Faktor Strategik Pelayanan Dosen dan Dampaknya terhadap Kepuasan Mahasiswa Fkip Universitas Muhamadiyah Surakarta Tahun Akademik 2005-2006', Varidika, 19(1), pp. 66-74.

Supranto, J., (2006). Pengukuran Tingkat Kepuasan Pelanggan. Jakarta: PT. Rineka Cipta.

Tuan, N. M. (2012) 'Effects of service quality and price fairness on student satisfaction', International Journal of Business and Social Science, 3(19 October), pp. 132-151. 
Article Metadata:

Sumianti. Syamsuddin. Nurhalimah, S. Hasbullah. Herlina. Musjuliana. (2020). An Analysis of Students' Satisfaction Level on Academic Administration Services of the Employees of IAIN Kendari.Ta'dib, 23 (1), 29-38.

http://dx.doi.org/10.31958/jt.v23i1.1821

Keywords: College Student Satisfaction, Academic Administration Services

Coresponding author: Syamsuddin, IAIN Kendari, syamsuddinjufry@gmail.com 